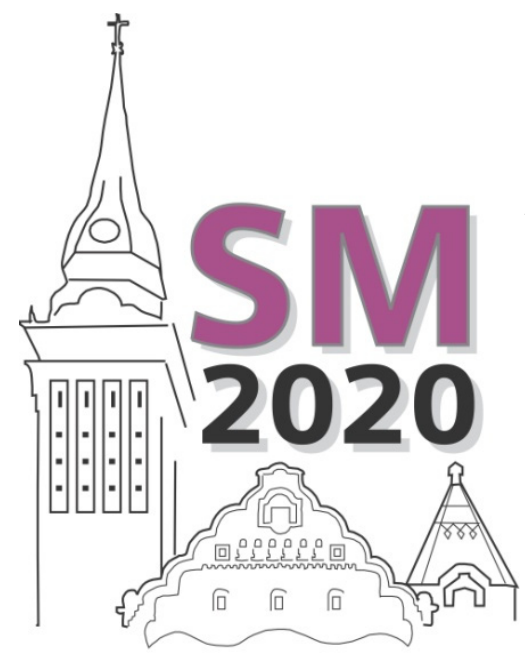

Tatiana Stuken

Dostoevsky Omsk State University, Omsk, Russia

Stuken@mail.ru

25th International Scientific Conference

Strategic Management and Decision Support Systems

in Strategic Management

$19^{\text {th }}$ May, 2020, Subotica, Republic of Serbia

\title{
THE EFFICIENCY OF STATE EMPLOYMENT CENTERS: CASE OF RUSSIA
}

\begin{abstract}
Currently the national project "Labor productivity and employment support" is implementing in Russia a set of measures aimed at developing employment infrastructure and introducing organizational and technological innovations to support employment, including standard solutions aimed at improving the efficiency of state employment centers. This project defines the strategic directions of state regulation of the Russian labor market.

This article deals with the issues of the population's demand for the services of employment centers, including not only registering as unemployed but also receiving public services to assist in finding a suitable job, vocational training, psychological support, etc.

The study is based on the Russian labor force survey and microdata of employment centers for 2019 (more than 24,000 observations).

Based on the data from the labor force survey, there are drawn conclusions about the demand for the state employment centers' services among various groups of the population and about typical combinations of applying to the employment service with other job search channels.

The analysis of regional microdata made it possible to evaluate the performance of employment centers based on information about the socio-demographic characteristics of the unemployed, the duration of the unemployment status, the fact of receiving benefits, the services received and the reasons for de-registration.

Based on the results of the analysis, there are made conclusions about the ways to improve the work of the state employment centers.
\end{abstract}

Keywords: Active labor market policies, state employment centers.

\section{INTRODUCTION}

Development priorities of the Russian Federation until 2024 are defined by a series of national projects, one of which is the national project "Labor productivity and employment support". An integral part of this project is the modernization of employment centers, improving the efficiency of their work and the quality of services provided to the population. By the legislation of the Russian Federation, employment centers are assigned the following main functions:

- informing citizens about the situation on the labor market, rights, and guarantees in the field of employment and protection from unemployment,

- development and implementation of programs that provide for measures to promote employment,

- assistance to citizens in finding a suitable job, and to employers in selecting the necessary employees,

- organization of measures of active employment policy of the population,

- implementation of social payments to citizens recognized as unemployed following the established procedure (Employment of the population in the Russian Federation, 1991).

Considering the role of employment centers in the Russian labor market, it is important to note several features. 
1. There is a large gap between the overall unemployment rate, which is recorded by statistical agencies in accordance with international standards, and the unemployment rate recorded by employment centers. So, at the end of 2019 on average, total unemployment in Russia exceeded the registered unemployment rate by more than 4 times;

2. Perception of employment centers by labor market agents as generally ineffective bureaucratic structures. Applying to an employment center is not the most popular way to find a job (Gruznykh, 2015).

The cost of implementing services provided by employment centers is estimated to be quite high. Thus, OECD experts estimate the cost of implementing an active employment policy at $0.5 \%$ of GDP (Data on active labour market policies, 2017). As part of the implementation of national projects and tasks aimed at supporting employment, the Russian government plans to allocate 12.7 billion rubles (Passport of the national project (program) "Productivity and employment support", 2018).

Priorities of state policy, combined with significant financial resources, actualize the need to assess the effectiveness of employment centers.

Assessment of the effectiveness of employment centers can be carried out at the macro and micro levels.

In the first case, the effect of individuals' participation in employment center programs is estimated, which can be expressed, for example, in changes in the probability of getting a job, the onset of a repeated period of unemployment, its duration of unemployment, etc. (Vooren et al., 2019). Many researchers have recorded a small positive effect from the implementation of active employment policy measures (Crépon, van den Berg, 2016; Card et al., 2018). At the same time, it is noted that different programs of employment centers have different microeconomic efficiency. For example, it is shown that the greatest impact on improving the position of labor market participants has assistance in finding a job (Kluve, 2010; Vooren et al., 2019).

The macroeconomic effects of employment center programs are analyzed in the context of the unemployment rate and are usually based on cross-country (inter-regional) comparisons. Thus, A. Bánociová et al. (Bánociová et al., 2017) based on an analysis of data from $21 \mathrm{EU}$ countries found that increases in spending on active employment policy programs were not significantly reflected in changes in the unemployment rate. In the work of L. Benda et al. (Benda et al., 2019) it was revealed that the effectiveness of an active employment policy depends on institutional factors, namely, the strictness of employment protection legislation and the "generosity" of unemployment benefits. Active employment programs have different effects on long-term unemployment, depending on the institutional configuration of the labor market. Government employment and training programs help reduce long-term unemployment with stricter employment protection laws. Employment programs become more effective when the "generosity" of unemployment benefits decreases.

Currently, Russian regions are evaluating the activities of employment centers. However, the analysis of used indicators and criteria shows that often, in the evaluation the focus is more on internal processes than on the effects for beneficiaries and the labor market in general:

- performance (performance of the state task on the provision of public services, the achievement of established performance indicator),

- indicators of financial and economic activity;

- indicators of personnel performance (staffing and staff turnover).

In this paper there is made an attempt to evaluate the activity of the employment service from the perspective of service recipients on the example of one of the 85 Russian regions based on data available in employment centers and state statistics bodies. This region can be called a typical region of the country based on its total population, share of urban population, education level, employment structure, and unemployment rate. The characteristics of employment centers may reflect the situation in other Russian regions, both because of the typical nature of this region, and because of the existence of national formal rules governing their work.

\section{RESEARCH METHODS}

The purpose of this study is to evaluate the effectiveness of employment centers at the micro level using statistical data, as well as to determine on this basis the directions for improving the activities of employment centers.

It is important to note that such an assessment objectively faces several difficulties.

1. Conducting research related to the implementation of any programs with the subsequent comparison of experimental and control groups for objective reasons is difficult because it involves the choice of individuals who will be provided this or that support, and who will not be provided, not based on the current legislation. Therefore, the main emphasis is on the use of economic and mathematical methods, econometric analysis;

2. In addition to the methods used, in the microeconomic assessment of the effectiveness of employment centers, it is important to have an information base with the characteristics of individuals who have applied to employment centers, containing information about the services they receive and the reasons for de-registration. The quality of the assessment is largely determined by the quality of the information base;

3. Qualitative analysis involves not only an assessment of what services the employment centers provided to the individual and for what reasons he was removed from the register in the employment center, but also how his position in the labor market changed after a certain period. For example, the effectiveness of the employment center, all other things being equal, will be evidenced by the presence of stable paid employment, while job loss and long-term repeated unemployment, on the contrary, will reduce the effectiveness estimates. However, the analysis of an individual's position 
in the labor market after being de-registered in an employment center is difficult both because of the legislation on personal data protection, which requires the individual's prior consent to collect information, and because the individual may refuse to answer questions or change their contact information, etc.

This is why in this study, the tasks of evaluating the effectiveness of employment centers are adjusted to take into account the available information. We have two microdata databases at our disposal that are used to build estimates.

1. Database of the 2017-2018 monthly sample survey of the labor force, representative for each of the Russian regions. It contains information about the socio-demographic characteristics of the population (gender, age, education, place of residence, classification as unemployed), methods of job search;

2. Microdata of regional employment centers containing information about the socio-demographic characteristics of individuals registered as unemployed (gender, age, education, place of residence), the date of registration and deregistration (if available), the list of services used by the unemployed, the reasons for deregistration.

The available data allow us to evaluate the effectiveness of employment centers for individuals in the following areas:

1. Availability of employment centers services for the population. The location of employment centers and the list of documents required to register an individual as unemployed and to assign benefits may create certain barriers, especially for people with low education levels and living in rural areas with low population density;

2. Reasons for deregistration of the unemployed, which may characterize the usefulness of the services received for individuals. For example, the reasons that can characterize a positive impact on the position of an individual in the labor market include various employment options, vocational training (following Russian legislation, vocational training is the basis for deregistration of an unemployed person), as well as the organization of their own business (business activity). Negative assessments of the employment service's performance may be related to such reasons for deregistration as refusal of employment center services, or long-term absence from the employment center without a valid reason. The difference between these reasons is that in the first case, the person receives unemployment benefits, and in the second case does not;

3. The list and number of activities carried out by employment centers concerning the unemployed and their impact on the reasons for de-registration.

The following analysis methods are used: descriptive statistics, as well as regression analysis (logistic regression).

\section{RESEARCH RESULTS}

For analysis of accessibility of services of employment centers, we used data from the labor force survey. A sub-sample of people living in the region and classified as unemployed by international standards amounted to 129.4 thousand observations. The frequency of calls to employment centers by socio-demographic characteristics is shown in table 1 .

Table 1: Using the services of employment centers when searching for a job (\% of the number of unemployed in the corresponding group)

\begin{tabular}{|l|c|c|}
\hline Factor & $\begin{array}{l}\text { Searching for a job with the } \\
\text { help of an employment center }\end{array}$ & $\begin{array}{l}\text { Searching for a job } \\
\text { without the help of an } \\
\text { employment center }\end{array}$ \\
\hline Residence & & \\
\hline city & 25,8 & 74,2 \\
\hline rural area & 46,5 & 53,5 \\
\hline Gender & 32,7 & 67,3 \\
\hline male & 32,1 & 67,9 \\
\hline female & & \\
\hline Age & 25,8 & 74,2 \\
\hline under 30 years old & 39,9 & 60,2 \\
\hline from 30 to 50 years old & 37,0 & 63,0 \\
\hline from 50 to 60 years old & & 70,6 \\
\hline Level of education & 29,4 & 64,5 \\
\hline do not have a professional education & 35,5 & 67,9 \\
\hline secondary professional education & 32,1 & 67,6 \\
\hline higher education & 32,4 & \\
\hline Total & \multicolumn{2}{|c|}{ Source: Stuken, Korzhova, 2020. } \\
\hline \multicolumn{2}{|l}{}
\end{tabular}

According to the table, it can be concluded that rural residents use the services of employment centers more often than urban residents. This may be due to limited opportunities to find work in rural areas and lower-income levels of rural residents, which makes the services of employment centers more attractive.

We also note that the services of employment centers are much less attractive to young people. With no work experience, young people can often only rely on the minimum amount of unemployment benefits. At the same time, the table does 
not confirm the widespread opinion that employment centers are mainly used by low-skilled workers. It is employees without professional education who are less likely to become clients of employment centers. This fact requires further study. The reasons for this situation may be, for example, lower awareness of this group of unemployed, a high prevalence of informal employment, the complexity of bureaucratic procedures, etc.

A more accurate assessment of the availability of employment centers services for unemployed individuals was performed using a binary logistic regression, which also included variables that characterize the individual's marital status, the reasons for the loss of previous work and the group of occupations at the last job, and the duration of unemployment. The results of the research generally confirmed the data of descriptive statistics. All other things being equal, urban residents are less likely to apply to employment centers, and those who are married, have children, those who are over 30 years old, and those who have lost their jobs due to staff cuts and the end of the contract are more likely to apply to employment centers (in all cases $\mathrm{p}<0.01$ ).

The assessment of the impact of an individual's qualifications on applying to the employment center was ambiguous. Thus, people with higher or secondary professional education are more likely to apply to employment centers than those without professional education $(\mathrm{p}<0.01)$. Individuals who have held positions of managers and mid-level specialists apply to employment centers less often than people who previously worked in the jobs of skilled and unskilled workers ( $p<0.01)$. However, all other things being equal, highly qualified specialists apply to employment centers more often than skilled and unskilled workers $(\mathrm{p}<0.01)$. This may probably be due to the specifics of the labor market and the oversupply of highly qualified specialists.

Unexpected results were obtained when analyzing the impact of applying to the employment service and the duration of unemployment. It is logical to assume that the need for employment center services should increase as the duration of unemployment increases. However, no such link was found. On the contrary, the need for employment center services decreases with increasing duration of unemployment $(\mathrm{p}<0.01)$.

Russian employment centers provide their clients with a wide range of services, including informing about the situation on the labor market, assistance in finding a suitable job, organization of paid public works, assistance in self-employment of unemployed citizens, vocational training and additional vocational education, the professional orientation of citizens to choose a field of activity (profession), psychological support, organization of support for the employment of disabled people. The most complete set of services an individual receives after registering at the employment center as an unemployed person. Following Russian legislation, unemployed citizens have the right to receive free psychological support, professional training in the direction of the employment center. It is for the unemployed that employment centers have the most complete statistics, which allows us to analyze the reasons for their deregistration (table 2).

Table 2. Distribution of reasons for deregistration of the unemployed in employment centers (\% of the number of cases)

\begin{tabular}{|l|c|}
\hline \multicolumn{1}{|c|}{ Reasons for deregistration } & Percentage, \% \\
\hline Temporary employment & 2,29 \\
\hline Employment for public works & 3,54 \\
\hline Employment in a subsidized workplace & 0,78 \\
\hline Employment in the direction of the employment center & 18,67 \\
\hline Self-employment & 28,25 \\
\hline Long absence from the employment center for no valid reason & 15,72 \\
\hline Refusal of employment center services & 5,78 \\
\hline Business activity, organization of farming & 0,56 \\
\hline Vocational training & 22,19 \\
\hline Other reasons & 2,22 \\
\hline Total & 100 \\
\hline
\end{tabular}

Source: Stuken, Korzhova, 2020.

Slightly more than half of the unemployed (53.53\%) are deregistered for employment reasons. However, a significant part of employment is not directly related to the activities of employment centers. Self-employment accounts for more than half of all employment (52.8\%). However, this does not indicate the inefficient work of employment centers, since a number of services provided by them are aimed at improving the competitiveness of the unemployed and selfemployment search. However, applying to the employment center does not have a high correlation with other methods of job search (the maximum correlation coefficient is 0.22 (when compared with direct application to the organization, $\mathrm{p}<0.01)$.

Obtaining a professional education in accordance with Russian law, although it is the basis for the deregistration of an unemployed person, does not indicate that the unemployed person will find work in a new profession. Unfortunately, employment centers do not have the necessary resources to track the further trajectories of the unemployed in the labor market, which would allow us to more accurately determine the effect of services provided to the unemployed.

According to the data, every fifth unemployed person $(21.5 \%)$ is de-registered either by writing an application to refuse the services of the employment center or because of a long absence from the employment center for no valid reason. Despite the negative nature of such reasons for de-registration, the actual situation may be somewhat more complicated. For example, a long absence may be related to the fact that an unemployed person who does not receive benefits is 
employed. In this situation, the unemployed person is not obliged to inform the employment center about their employment.

It should be noted that other reasons for deregistration include such as conscription into the armed forces, the appointment of an old-age pension, moving to another area, detection of attempts to obtain fraudulently, etc.

According to the data, $70 \%$ of the unemployed re-apply to the employment service sometime after being deregistered.

To assess the effectiveness of employment centers, it is important to analyze the services provided to clients by employment centers and identify their relationship to the reasons for deregistration. Available information shows that the frequency of service provision is uneven. For example, almost all unemployed people receive services related to informing about the situation on the labor market and assistance in finding a suitable job (more than 95\%), professional guidance (more than 80\%). At the same time, other services are provided much less frequently (table 3 ). The average number of services received by one unemployed person is 4.2 .

Table 3. Distribution of employment centers' services by frequency of their provision (\% of clients who received the corresponding service)

\begin{tabular}{|l|c|}
\hline \multicolumn{1}{|c|}{ Services } & $\begin{array}{c}\text { Percentage of clients who } \\
\text { received the service, \% }\end{array}$ \\
\hline Informing about the situation on the labor market & 95,3 \\
\hline Temporary employment & 2,1 \\
\hline The promotion of self-employment & 5,6 \\
\hline Social adaptation & 13,9 \\
\hline Psychological support & 17,4 \\
\hline Public works & 4,8 \\
\hline Peofessional training & 15,1 \\
\hline Assistance in job search & 95,5 \\
\hline Professional guidance & 80,5 \\
\hline
\end{tabular}

Source: Stuken, Korzhova, 2020.

To analyze the impact of services received on the reasons for deregistration, we used logistic regression models. The main reasons for deregistration were consistently used as dependent variables:

1. Self-employment or employment in the direction of the employment service. Both options can characterize the clients of the employment center as having sufficient competitiveness in the labor market;

2. Employment in subsidized jobs, public works (for some groups of the unemployed, such work is appropriate under Russian law), temporary employment of people who are experiencing difficulties in finding work. Such employment is less stable and less preferable for the individual;

3. Professional training. Following Russian legislation, employment centers send to professional training those citizens who do not have a profession, cannot find a job in their existing profession or qualification or have lost the ability to perform work in their existing profession (qualification).

We have divided the factors that influence the reasons for deregistration into two groups.

The first category includes characteristics of individuals: place of residence (a large city that is the administrative center of the region, or other localities), gender of the respondent (male, female), age (under 25 years, 25-40 years, from 40 years to pre-retirement age; pre-retirement age (according to Russian legislation, it includes the age corresponding to five or fewer years before the age of retirement); level of education (higher, secondary professional, no professional education); duration of the unemployment period (up to 1 month, 1-3 months, 3-6 months, more than 6 months), experience in the labor market (up to 1 year or more), health status (presence or absence of disability), repeated application to the employment center.

The second group includes the services of employment centers provided to the unemployed and indicated in table 3 above, with the exception of those that, for certain reasons, are either mandatory or cannot be provided. These services include self-employment promotion (for all models), referral to vocational training (for all models), temporary employment (for all models), and participation in public works for model 2.

Let's look at the main results. For convenience, table 4 shows only statistically significant estimates of regression parameters and the direction of the variable's influence on the result.

Table 4: Influence of various factors on the probability of deregistration of the unemployed by reason Independent variables (factors) Dependent variable (reason for de-registration) 


\begin{tabular}{|c|c|c|c|}
\hline & $\begin{array}{l}\text { Model 1. Employment } \\
\text { independently or with } \\
\text { the help of an } \\
\text { employment center }\end{array}$ & $\begin{array}{c}\text { Model 2. } \\
\text { Employment for } \\
\text { temporary jobs, public } \\
\text { works, subsidized jobs }\end{array}$ & $\begin{array}{l}\text { Model } 3 . \\
\text { Professiona } \\
\text { training }\end{array}$ \\
\hline \multicolumn{4}{|l|}{ Services of employment centers: } \\
\hline Social adaptation & $+* * *$ & $+* * *$ & $+* * *$ \\
\hline Public works & $-{ }_{-* * *}^{* *}$ & & $-* * *$ \\
\hline Assistance in job search & $t^{* \star *}$ & $--^{* * \star}$ & \\
\hline Psychological support & & & $+* * *$ \\
\hline Professional guidance & $-{ }^{-* \star *}$ & $-{ }^{-* * *}$ & $t^{\star \star \star}$ \\
\hline \multicolumn{4}{|l|}{ Characteristics of respondents: } \\
\hline Place of residence (regional center - ref.) & $-{ }^{* * *}$ & $-{ }^{* * *}$ & \\
\hline Gender (female - ref.) & $-{ }^{*}$ & $-* * *$ & $t^{\star \star \star}$ \\
\hline \multicolumn{4}{|l|}{ Education (no professional education - ref.): } \\
\hline Higher & $+* * *$ & $-{ }^{* * *}$ & $-{ }^{* * *}$ \\
\hline Secondary professional education & $t^{\star \star \star}$ & $--^{* * *}$ & $--^{* * *}$ \\
\hline \multicolumn{4}{|l|}{ Age (40-50 for women, $40-55$ for men - ref.): } \\
\hline Age up to 25 years & & $-* * *$ & $+* * *$ \\
\hline $\begin{array}{l}\text { Pre-retirement age (51-55 for women, } 56-60 \\
\text { for men ) }\end{array}$ & $-* * *$ & $+{ }^{* * *}$ & $-^{* * *}$ \\
\hline Disability (absence - ref.) & $-{ }^{* * *}$ & $t^{* * *}$ & $-{ }^{* * *}$ \\
\hline $\begin{array}{l}\text { Work experience in the labor market for a } \\
\text { year or less (more than } 1 \text { year - ref.) }\end{array}$ & $-* * *$ & $+* * *$ & $+* * *$ \\
\hline $\begin{array}{l}\text { Repeated application to the employment } \\
\text { center (primary - ref.) }\end{array}$ & & & $+* * *$ \\
\hline \multicolumn{4}{|l|}{$\begin{array}{l}\text { Duration of the unemployment period (more } \\
\text { than } 6 \text { months - ref.): }\end{array}$} \\
\hline up to 1 month & $t^{\star * *}$ & $+* * *$ & $+* * *$ \\
\hline from 1 to 3 months & $+t^{* * *}$ & $+t^{* * *}$ & $+t^{* * *}$ \\
\hline from 3 to 6 months & $+* * *$ & $+t^{* * *}$ & $+* * *$ \\
\hline Nagelkerke R-square & 0,345 & 0,202 & 0,493 \\
\hline
\end{tabular}

${ }^{* \star *} p<0,01,{ }^{* *} p<0,05,{ }^{*} p<0,1$

Source: Stuken, Korzhova, 2020.

According to the data, in all the models considered, the provision of social adaptation services in the labor market, which allows the unemployed to learn how to make a resume, independently search for a job, prepare for an interview, etc., has a positive effect on the deregistration of the unemployed. The other services considered also have a certain effect, but not in all cases. For example, providing professional guidance is effective only if the unemployed person then agrees to take the professional training. Probably, the individual's awareness of the need to change the type of activity leads to the fact that the psychological support service, in this case, has a statistically significant positive impact. Assistance in searching for a job has an effect if the unemployed person has sufficient competitiveness to allow him to apply for a job on an equal basis with other individuals.

Let us also draw attention to the results obtained with regard to the participation of the unemployed in public works. The negative impact on deregistration in the first and third models may be due to the fact that participation in public works distracts the unemployed from participating in other programs.

As for the socio-demographic characteristics of the respondents, their estimates were generally expected. Lower employment rates in the regional center indicate that in a large city that has more opportunities in the labor market; individuals have more opportunities to find work without applying to employment centers. In other words, in the regional center, when applying to the employment center, there is a self-selection effect, while in small localities it is much weaker. The effect of self-selection, in our opinion, can be explained by the higher rates of employment in the regional center of women compared to men.

The problem group, despite a number of measures taken by the state, remains disabled people and people of pre-retirement age, who have less chance of employment and training. Their more active employment in temporary jobs and participation in public works partially compensates for the objectively lower competitiveness of this group of unemployed, as well as discrimination in the Russian labor market, including age discrimination.

\section{CONCLUSION}

The analysis makes it possible to conclude that the services of employment centers are available to the population, regardless of the place of residence. At the same time, it is important to pay attention to the availability and attractiveness of services for young people and people with low levels of education - groups that traditionally have higher than average unemployment rates. 
The majority of the unemployed are de-registered in employment centers in connection with employment. However, the quality of employment varies significantly. Almost $47 \%$ of the unemployed find work either on their own or in the direction of employment centers. The remaining part of the employed $(6.6 \%)$ is employed in less stable jobs - temporary work, subsidized jobs, and public works. More often than other groups of unemployed, this reason is typical for people of pre-retirement age who do not have work experience, and disabled people - groups that are particularly in need of assistance from the state.

A positive characteristic of the activity of the employment service can also serve as professional training for $15 \%$ of unemployed citizens. Most often, this service is used by young people and people who have repeatedly applied to the employment center. The data also shows that the indicators of employment and professional training are statistically significantly lower for the unemployed, whose duration of job search exceeds six months. There is required a more indepth analysis of this group, including their motivation to find work and the specifics of local labor markets.

We should also note the problems associated with the fact that the activity of employment centers does not fully meet the expectations of citizens. Among the indicators of these problems, it can be noted that every fifth unemployed person stops using the services of the employment center before reaching the goal of applying, and $70 \%$, being deregistered, again apply for a suitable job.

Thus, increasing the activity of employment centers can be associated with solving the following problems.

1. Increasing the attractiveness of employment centers ' services by increasing the minimum amount of unemployment benefits, which are extremely low for people without work experience and/or official earnings.

2. Increasing the use of online services to obtain employment services, which will increase the availability of services and reduce bureaucratic barriers and waiting times.

3. Building feedback with clients of employment centers, collecting and analyzing information in the context of the quality of jobs for which the unemployed are employed, tracking their further trajectories in the labor market over a certain period (for example, one year).

\section{ACKNOWLEDGMENTS}

Funding: The reported study was funded by RFBR, project number 20-010-00489

\section{REFERENCES}

Banociova, A. \& Ťahlová, S. (2017). Active Labour Market Policies of Selected European Countries and Their Competitiveness. Journal of Competitiveness. Vol. 9, 5-21.

Benda L., Koster F.\& van der Veen R. (2019). Activation is not a panacea: active labour market policy, longterm unemployment and institutional complementarity. Journal of Social Policy, 1-24.

Card, D. E., Kluve, J. \& Weber, A.M. (2018) What Works? A Meta Analysis of Recent Active Labor Market Program Evaluations. Journal of the European Economic Association, Vol. 16, Issue 3, 894-931.

Crepon, B. \& van den Berg, G. J. (2016) Active Labor Market Policies. Annual Review of Economics, Vol. 8, 521-546.

Data on active labour market policies (2017). Retrieved from https://www.oecd.org/employment/activation.htm

Gruznykh, S. (2015). New image of the employment service-improving the efficiency of labor market participants. Bulletin of Tomsk State University, 205-208.

Kluve, J. (2010). The Effectiveness of European Active Labor Market Policy. Labour Economics. Vol. 17, 904918.

Law of the Russian Federation N 1032-1 (1991). "Employment of the population in the Russian Federation". Retrieved from http://www.consultant.ru/document/cons_doc_LAW_60/

Passport of the national project (program) "Productivity and employment support" (2018). Retrieved from http://static.government.ru/media/files/Ki3g5TzKdmVyX2ogBvNTIxH3BQ6YFADA.pdf

Vooren, M., Haelermans, C., Maassen van den Brink, H. \& Groot, W. (2019). The Effectiveness of Active Labor Market Policies: A Meta-Analysis. Journal of Economic Surveys, Vol. 33, Issue 1, 125-149. 